\title{
Three-Dimensional Vibration Analysis of Rectangular Thick Plates on Pasternak Foundation with Arbitrary Boundary Conditions
}

\author{
Huimin Liu, ${ }^{1,2}$ Fanming Liu, ${ }^{1}$ Xin Jing, ${ }^{1}$ Zhenpeng Wang, ${ }^{1}$ and Linlin Xia ${ }^{3}$ \\ ${ }^{1}$ College of Automation, Harbin Engineering University, Harbin, China \\ ${ }^{2}$ College of Mechanical and Electrical Engineering, Qingdao Agricultural University, Qingdao, China \\ ${ }^{3}$ School of Automation Engineering, Northeast Dianli University, Jilin, China \\ Correspondence should be addressed to Fanming Liu; hrblfm407@126.com
}

Received 9 December 2016; Revised 10 March 2017; Accepted 3 April 2017; Published 22 May 2017

Academic Editor: Anindya Ghoshal

Copyright ( 2017 Huimin Liu et al. This is an open access article distributed under the Creative Commons Attribution License, which permits unrestricted use, distribution, and reproduction in any medium, provided the original work is properly cited.

\begin{abstract}
This paper presents the first known vibration characteristic of rectangular thick plates on Pasternak foundation with arbitrary boundary conditions on the basis of the three-dimensional elasticity theory. The arbitrary boundary conditions are obtained by laying out three types of linear springs on all edges. The modified Fourier series are chosen as the basis functions of the admissible function of the thick plates to eliminate all the relevant discontinuities of the displacements and their derivatives at the edges. The exact solution is obtained based on the Rayleigh-Ritz procedure by the energy functions of the thick plate. The excellent accuracy and reliability of current solutions are demonstrated by numerical examples and comparisons with the results available in the literature. In addition, the influence of the foundation coefficients as well as the boundary restraint parameters is also analyzed, which can serve as the benchmark data for the future research technique.
\end{abstract}

\section{Introduction}

Rectangular plates as the common structural components have been extensively used in various engineering fields such as aerospace, military, and marine industries. Thus, the knowledge of vibration characteristics of the rectangular plates is of particular importance for the predesign of the engineering structures. In general, the analysis for the vibration problem of the rectangular plates is based on the classical thin plate theory [1] and two-dimensional approximate theories [2-5], that is, first-order shear deformation theory and higher-order deformation theory. However, the present results indicate that the two-dimensional plate theories have shortcomings [6-8]. For the classical thin plate theory, it neglects the effect of the transverse shear deformation by the simplified assumption that the normal to the undeformed mid-plane remains normal after deformation. For case of the two-dimensional approximate theories, the shear factor strongly relies on the boundary condition and they often need more hardware resources to obtain proper accuracy solution. Based on the above analysis, the three-dimensional elastic theory is presented to overcome the weakness of the two-dimensional plate theories, which does not rely on any hypotheses or deserve any numerical precision and can be used to solve the vibration problem of thick rectangular plates.

Over the past several decades, the three-dimensional vibration analyses of thick rectangular plates have been investigated by many researchers. Srinivas et al. [9] analyzed the free vibration of thick rectangular plates by the direct method based on the three-dimensional linear, small deformation theory. In their study, the boundary condition is limited to the all simply supported case on four edges. Cheung and Chakrabarti [10] used the finite layer method which is an extension of the well-known finite element method to study the free vibration of rectangular plates with various classical boundary conditions on the basis of the threedimensional linear, small deformation theory. Hutchinson and Zillmer [11] used the series solution method to analyze the free vibration of a completely free parallelepiped. Fromme 
and Leissa [12] extended the Fourier method to investigate the free vibration of the rectangular parallelepiped with simple classical boundary conditions based on the threedimensional elasticity theory. On the basis of the threedimensional elasticity theory and differential quadrature method (DQM), Malik and Bert [13], Liew and Teo [14], and Liew et al. [15] investigated the free vibration characteristics of rectangular plates with some selected classical boundary conditions. Leissa and Zhang [16] employed the Ritz method to study the three-dimensional problem of determining the free vibration frequencies and mode shapes for a rectangular parallelepiped which is completely fixed on one face and free on other five faces. In this research, the displacements of the rectangular parallelepiped are assumed in the form of algebraic polynomials. Also, Liew et al. [17-19] applied the Ritz method and the three-dimensional elastic theory to establish the continuum three-dimensional Ritz formulation to study the vibration characteristic of the thick rectangular plates with classical boundary conditions. The orthogonally generated polynomial functions are used as admissible functions to make analysis in such plates. Itakura [20] adopted the three-dimensional theory to study the free vibration of rectangular thick plate with classical boundary conditions. Lim et al. [21, 22] presented a concise formulation and an efficient method of solution to study the free vibration of thick, shear deformable plates with classical boundary conditions. Zhou et al. [23] used the Chebyshev polynomials as admissible functions and applied Ritz method to study the three-dimensional vibration of rectangular plates with classical boundary conditions.

By means of the review of the above references, most of the studies for the vibration problem of the thick rectangular plates do not consider the elastic foundations. However, a lot of engineering problems boil down to a rectangular plate on elastic foundations, such as footing of buildings, pavement of roads, and base of heavy machines. In the practical application, the Pasternak model (also referred to as the two-parameter model) [24-26] is widely used to describe the mechanical behavior of the foundation, in which the wellknown Winkler model [27] is a special case. In addition, the boundary condition may not always be classical case in reality, and a variety of possible boundary conditions including classical boundary conditions, elastic boundary restraints, and the combinations of two or more conditions may be encountered [6-8, 28-47]. Based on the open published paper, we can know that merely Zhou et al. [48, 49] extended the Chebyshev-Ritz method to study the free vibration characteristics of rectangular thick plates and thick circular plates resting on elastic foundations, respectively. However, it should be noted that the boundary conditions are limited to the FFFF, SSSS, and CCCC classical boundary conditions. There is no work reported on the free vibration behavior of rectangular thick plates on Pasternak foundation with general boundary conditions. Thus, to present a new three-dimensional exact solution for the free vibrations of rectangular thick plates with arbitrary boundary conditions is of crucial importance.

In this paper, the first known three-dimensional vibration characteristic of rectangular thick plates on Pasternak foundation with arbitrary boundary conditions is studied. The theoretical formulations are based on the threedimensional linear, small-strain elasticity theory. The modified Fourier series are chosen as the basis functions of the admissible function of the thick plates in the Ritz method. The arbitrary boundary conditions are obtained by laying out three types of liner springs on all edges. The excellent accuracy and reliability of current solutions are demonstrated by numerical examples and comparisons with the results available in the literature. In addition, the influence of the foundation coefficients as well as the boundary restraint parameters are also analyzed, which can serve as the benchmark data for the future research technique.

\section{Theoretical Formulations}

Consider a rectangular thick plate on Pasternak foundation with arbitrary boundary conditions as shown in Figure 1. A Cartesian coordinate $(x, y, z)$ is also shown in the Figure 1 , which will be used in the analysis. $U, V$, and $W$ denote the displacement components in $x, y$, and $z$ directions. Length, width, and thickness of the rectangular thick plates are assumed as $a, b$, and $h$, respectively. As shown in Figure 1, three groups of linear restraint springs are arranged at all sides of the rectangular thick plates to separately simulate the arbitrary boundary conditions. The undersurface of the plate is continuously rested on an elastic foundation represented by the Winkler/Pasternak model, in which the Winkler and shear stiffness are denoted by $K_{w}$ and $K_{s}$, respectively, seen from Figure 1.

According to the three-dimensional elasticity theory, the strain components of rectangular thick plates can be expressed as

$$
\begin{aligned}
\varepsilon_{x} & =\frac{\partial u}{\partial x}, \\
\varepsilon_{y} & =\frac{\partial v}{\partial y}, \\
\varepsilon_{z} & =\frac{\partial w}{\partial z}, \\
\gamma_{x y} & =\frac{\partial v}{\partial x}+\frac{\partial u}{\partial y}, \\
\gamma_{x z} & =\frac{\partial w}{\partial x}+\frac{\partial u}{\partial z} \\
\gamma_{y z} & =\frac{\partial v}{\partial z}+\frac{\partial w}{\partial y} .
\end{aligned}
$$

Based on Hooke's law, the corresponding stress-strain relations of the rectangular thick plates can be written as

$$
\begin{aligned}
\sigma_{x} & =(\Upsilon+2 \Theta) \varepsilon_{x}+\Upsilon \varepsilon_{y}+\Upsilon \varepsilon_{z}, \\
\sigma_{y} & =\Upsilon \varepsilon_{x}+(\Upsilon+2 \Theta) \varepsilon_{y}+\Upsilon \varepsilon_{z}, \\
\sigma_{z} & =\Upsilon \varepsilon_{x}+\Upsilon \varepsilon_{y}+(\Upsilon+2 \Theta) \varepsilon_{z}, \\
\tau_{x y} & =\Theta \gamma_{x y},
\end{aligned}
$$



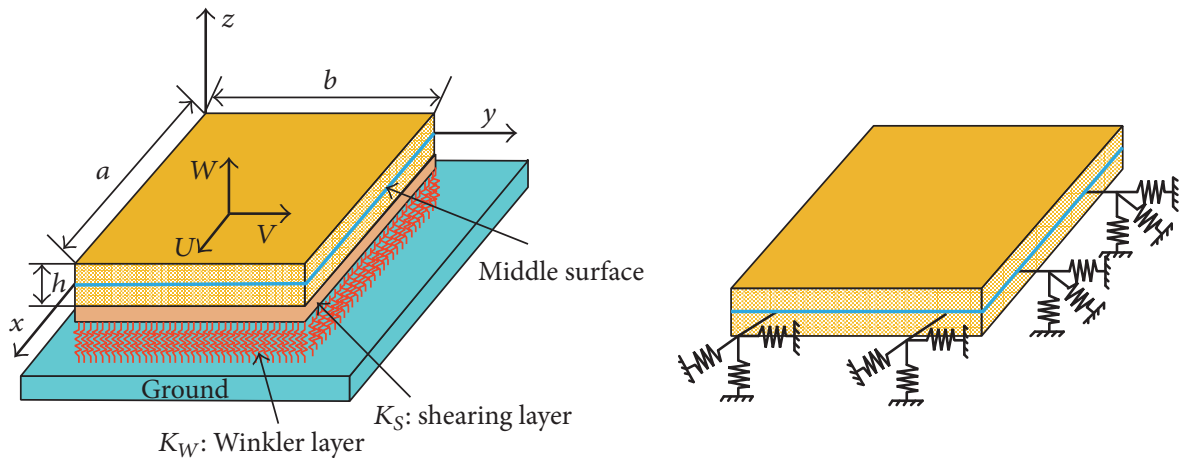

FIGURE 1: The rectangular thick plates in contact with elastic foundation with general elastic boundary conditions.

$$
\begin{aligned}
& \tau_{x z}=\Theta \gamma_{x z}, \\
& \tau_{y z}=\Theta \gamma_{y z},
\end{aligned}
$$

where $\Upsilon$ and $\Theta$ are as follows:

$$
\begin{aligned}
& \Upsilon=\frac{E \mu}{(1+\mu)(1-2 \mu)}, \\
& \Theta=\frac{E}{2(1+\mu)}
\end{aligned}
$$

in which $E$ and $\mu$ are Young's modulus and Poisson's ratio of the rectangular thick plates. The strain energy $U$ for rectangular thick plates is given in integral form by

$$
\begin{aligned}
U & =\frac{1}{2} \iiint_{V}\left\{\varepsilon_{x} \sigma_{x}+\varepsilon_{y} \sigma_{y}+\varepsilon_{z} \sigma_{z}+\gamma_{x y} \tau_{x y}+\gamma_{x z} \tau_{x z}\right. \\
& \left.+\gamma_{y z} \tau_{y z}\right\} d x d y d z \\
& =\frac{1}{2} \int_{0}^{a} \int_{0}^{b} \int_{0}^{h}\left\{(\Upsilon+2 \Theta)\left[\left(\frac{\partial u}{\partial x}\right)^{2}+\left(\frac{\partial v}{\partial y}\right)^{2}+\left(\frac{\partial w}{\partial z}\right)^{2}\right]\right. \\
& +2 \Upsilon\left[\frac{\partial u}{\partial x} \frac{\partial v}{\partial y}+\frac{\partial v}{\partial y} \frac{\partial w}{\partial z}+\frac{\partial w}{\partial z} \frac{\partial u}{\partial x}\right] \\
& +2 \Theta\left[\frac{\partial u}{\partial y} \frac{\partial v}{\partial x}+\frac{\partial v}{\partial z} \frac{\partial w}{\partial y}+\frac{\partial w}{\partial x} \frac{\partial u}{\partial z}\right] \\
& +\Theta\left[\left(\frac{\partial u}{\partial y}\right)^{2}+\left(\frac{\partial v}{\partial x}\right)^{2}+\left(\frac{\partial w}{\partial x}\right)^{2}\right. \\
& \left.\left.+\left(\frac{\partial u}{\partial z}\right)^{2}+\left(\frac{\partial v}{\partial z}\right)^{2}+\left(\frac{\partial w}{\partial y}\right)^{2}\right]\right\} d x d y d z .
\end{aligned}
$$

The kinetic energy $T$ of the rectangular thick plates is depicted as

$$
\begin{aligned}
T & =\frac{1}{2} \\
& \cdot \rho \int_{0}^{a} \int_{0}^{b} \int_{0}^{h}\left[\left(\frac{\partial u}{\partial t}\right)^{2}+\left(\frac{\partial v}{\partial t}\right)^{2}+\left(\frac{\partial w}{\partial t}\right)^{2}\right] d x d y d z .
\end{aligned}
$$

As mentioned before, in this paper, the boundary conditions of the rectangular thick plates are the arbitrary boundary condition and obtained by laying out three types of linear springs on all the edges. Thus, the corresponding boundary conditions can be described as

$$
\begin{aligned}
& \sigma_{x}+k_{x 0}^{u} u=0, \\
& \tau_{x y}+k_{x 0}^{v} v=0, \\
& \tau_{x z}+k_{x 0}^{w} w=0 \\
& x=0 \\
& \sigma_{x}-k_{x 1}^{u} u=0, \\
& \tau_{x y}-k_{x 1}^{v} v=0, \\
& \tau_{x z}-k_{x 1}^{w} w=0 \\
& \tau_{x y}+k_{y 0}^{u} u=0, \\
& \sigma_{y}+k_{y 0}^{v} v=0, \\
& \tau_{y z}+k_{\theta 0}^{w} w=0 \\
& \tau_{x y}-k_{y b}^{u} u=0, \\
& \sigma_{y}-k_{y b}^{v} v=0, \\
& y=0
\end{aligned}
$$

and the potential energy $P$ stored in the boundary springs can be expressed as

$$
\begin{aligned}
P & =\frac{1}{2} \int_{0}^{b} \int_{0}^{h}\left\{\left[k_{x 0}^{u} u^{2}+k_{x 0}^{v} v^{2}+k_{x 0}^{w} w^{2}\right]_{x=0}\right. \\
& \left.+\left[k_{x a}^{u} u^{2}+k_{x a}^{v} v^{2}+k_{x a}^{w} w^{2}\right]_{x=a}\right\} d y d z \\
& +\frac{1}{2} \int_{0}^{a} \int_{0}^{h}\left\{\left[k_{y 0}^{u} u^{2}+k_{y 0}^{v} v^{2}+k_{y 0}^{w} w^{2}\right]_{y=0}\right. \\
& \left.+\left[k_{y 1}^{u} u^{2}+k_{y 1}^{v} v^{2}+k_{y 1}^{w} w^{2}\right]_{y=b}\right\} d x d z .
\end{aligned}
$$


The potential energy of the elastic foundation $\left(U_{p f}\right)$ is given as

$$
\begin{aligned}
& U_{p f}=\frac{1}{2} \\
& \cdot \int_{0}^{a} \int_{0}^{b}\left(K_{w} w^{2}+K_{s}\left(\frac{\partial w}{\partial x}\right)^{2}+K_{s}\left(\frac{\partial w}{\partial y}\right)^{2}\right) d x d y,
\end{aligned}
$$

where $K_{w}$ and $K_{s}$ are the stiffness of the Winkler layer and shear layer, respectively.

The total energy functional for the rectangular thick plates can be expressed as

$$
\prod=T-U-P-U_{p f} .
$$

For the free vibration of the plate, the displacement components can be expressed in terms of the displacement amplitude functions:

$$
\begin{gathered}
u(x, y, z, t)=U(x, y, z) e^{i \omega t}, \\
v(x, y, z, t)=V(x, y, z) e^{i \omega t}, \\
w(x, y, z, t)=W(x, y, z) e^{i \omega t},
\end{gathered}
$$

where $\omega$ denotes the eigenfrequency of the plate and $i=\sqrt{-1}$.

Each of the displacement amplitude functions $U(x, y, z)$, $V(x, y, z)$, and $W(x, y, z)$ is expressed, respectively, in the form of a three-dimensional (3D) Fourier cosine series supplemented with closed-form auxiliary functions introduced to eliminate all the relevant discontinuities of the displacement function and its derivatives at the edges; that is,

$$
\begin{aligned}
& U(x, y, z) \\
& =\sum_{m=0}^{\infty} \sum_{n=0}^{\infty} \sum_{q=0}^{\infty} A_{m n q} \cos \lambda_{m x} x \cos \lambda_{n y} y \cos \lambda_{q z} z \\
& +\sum_{m=0}^{\infty} \sum_{n=0}^{\infty}\left(a_{m n}^{1} \zeta_{z}^{1}(z)+a_{m n}^{2} \zeta_{z}^{2}(z)\right) \cos \lambda_{m x} x \cos \lambda_{n y} y \\
& +\sum_{m=0}^{\infty} \sum_{q=0}^{\infty}\left(a_{m q}^{3} \zeta_{y}^{1}(y)+a_{m q}^{4} \zeta_{y}^{2}(y)\right) \cos \lambda_{m x} x \\
& \quad \cdot \cos \lambda_{q z} z+\sum_{n=0}^{\infty} \sum_{q=0}^{\infty}\left(a_{n q}^{5} \zeta_{x}^{1}(x)+a_{n q}^{6} \zeta_{x}^{2}(x)\right) \cos \lambda_{n y} y \\
& \quad \cdot \cos \lambda_{q z} z, \\
& V(x, y, z) \\
& \quad=\sum_{m=0}^{\infty} \sum_{n=0}^{\infty} \sum_{q=0}^{\infty} B_{m n q} \cos \lambda_{m x} x \cos \lambda_{n y} y \cos \lambda_{q z} z \\
& +\sum_{m=0}^{\infty} \sum_{n=0}^{\infty}\left(b_{m n}^{1} \zeta_{z}^{1}(z)+b_{m n}^{2} \zeta_{z}^{2}(z)\right) \cos \lambda_{m x} x \cos \lambda_{n y} y
\end{aligned}
$$

$$
\begin{aligned}
& +\sum_{m=0}^{\infty} \sum_{q=0}^{\infty}\left(b_{m q}^{3} \zeta_{y}^{1}(y)+b_{m q}^{4} \zeta_{y}^{2}(y)\right) \cos \lambda_{m x} x \cos \lambda_{q z} z \\
& +\sum_{n=0}^{\infty} \sum_{q=0}^{\infty}\left(b_{n q}^{5} \zeta_{x}^{1}(x)+b_{n q}^{6} \zeta_{x}^{2}(x)\right) \cos \lambda_{n y} y \cos \lambda_{q z} z
\end{aligned}
$$

$W(x, y, z)$

$$
\begin{aligned}
& =\sum_{m=0}^{\infty} \sum_{n=0}^{\infty} \sum_{q=0}^{\infty} C_{m n q} \cos \lambda_{m x} x \cos \lambda_{n y} y \cos \lambda_{q z} z \\
& +\sum_{m=0}^{\infty} \sum_{n=0}^{\infty}\left(c_{m n}^{1} \zeta_{z}^{1}(z)+c_{m n}^{2} \zeta_{z}^{2}(z)\right) \cos \lambda_{m x} x \cos \lambda_{n y} y \\
& +\sum_{m=0}^{\infty} \sum_{q=0}^{\infty}\left(c_{m q}^{3} \zeta_{y}^{1}(y)+c_{m q}^{4} \zeta_{y}^{2}(y)\right) \cos \lambda_{m x} x \cos \lambda_{q z} z \\
& +\sum_{n=0}^{\infty} \sum_{q=0}^{\infty}\left(c_{n q}^{5} \zeta_{x}^{1}(x)+c_{n q}^{6} \zeta_{x}^{2}(x)\right) \cos \lambda_{n y} y \cos \lambda_{q z} z
\end{aligned}
$$

where $\lambda_{m x}=m \pi / a, \lambda_{n y}=n \pi / b, \lambda_{q z}=q \pi / h$, and $A_{m n q}, B_{m n q}$, and $C_{m n q}$ are the Fourier coefficients of threedimensional Fourier series expansions for the displacements functions, respectively. $a_{m n}^{1}, a_{m n}^{2}, a_{m q}^{3}, a_{m q}^{4}, a_{n q}^{5}, a_{n q}^{6}, b_{m n}^{1}, b_{m n}^{2}$, $b_{m q}^{3}, b_{m q}^{4}, b_{n q}^{5}, b_{n q}^{6}, c_{m n}^{1}, c_{m n}^{2}, c_{m q}^{3}, c_{m q}^{4}, c_{n q}^{5}$, and $c_{n q}^{6}$ are the supplemented coefficients of the auxiliary functions. The closed-form auxiliary functions are given as follows:

$$
\begin{aligned}
& \zeta_{x}^{1}(x)=\frac{a}{2 \pi} \sin \left(\frac{\pi x}{2 a}\right)+\frac{a}{2 \pi} \sin \left(\frac{3 \pi x}{2 a}\right), \\
& \zeta_{x}^{2}(x)=-\frac{a}{2 \pi} \cos \left(\frac{\pi x}{2 a}\right)+\frac{a}{2 \pi} \cos \left(\frac{3 \pi x}{2 a}\right), \\
& \zeta_{y}^{1}(y)=\frac{b}{2 \pi} \sin \left(\frac{\pi y}{2 b}\right)+\frac{b}{2 \pi} \sin \left(\frac{3 \pi y}{2 b}\right), \\
& \zeta_{y}^{2}(y)=-\frac{b}{2 \pi} \cos \left(\frac{\pi y}{2 b}\right)+\frac{b}{2 \pi} \cos \left(\frac{3 \pi y}{2 b}\right), \\
& \zeta_{z}^{1}(z)=\frac{h}{2 \pi} \sin \left(\frac{\pi z}{2 h}\right)+\frac{\phi}{2 \pi} \sin \left(\frac{3 \pi z}{2 h}\right), \\
& \zeta_{z}^{2}(z)=-\frac{h}{2 \pi} \cos \left(\frac{\pi z}{2 h}\right)+\frac{h}{2 \pi} \cos \left(\frac{3 \pi z}{2 h}\right) .
\end{aligned}
$$

It is easy to verify that

$$
\begin{aligned}
& \zeta_{x}^{1}(0)=\zeta_{x}^{1}(a)=\zeta_{x}^{1^{\prime}}(a)=0, \quad \zeta_{x}^{1^{\prime}}(0)=1, \\
& \zeta_{x}^{2}(0)=\zeta_{x}^{2}(a)=\zeta_{x}^{2^{\prime}}(0)=0, \quad \zeta_{x}^{2^{\prime}}(a)=1, \\
& \zeta_{y}^{1}(0)=\zeta_{y}^{1}(b)=\zeta_{y}^{1^{\prime}}(b)=0, \quad \zeta_{y}^{1^{\prime}}(0)=1, \\
& \zeta_{y}^{2}(0)=\zeta_{y}^{2}(b)=\zeta_{y}^{2^{\prime}}(0)=0, \quad \zeta_{y}^{2^{\prime}}(b)=1, \\
& \zeta_{z}^{1}(0)=\zeta_{z}^{1}(h)=\zeta_{z}^{1^{\prime}}(h)=0, \quad \zeta_{z}^{1^{\prime}}(0)=1,
\end{aligned}
$$




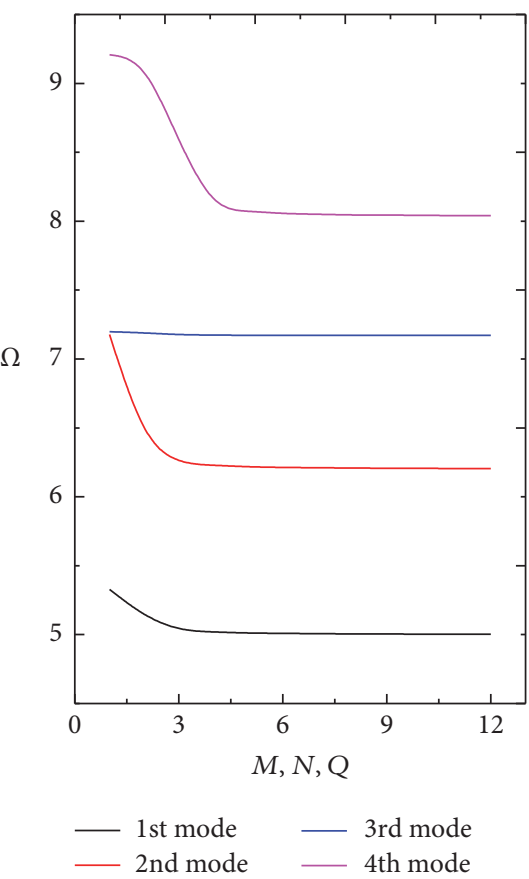

(a)

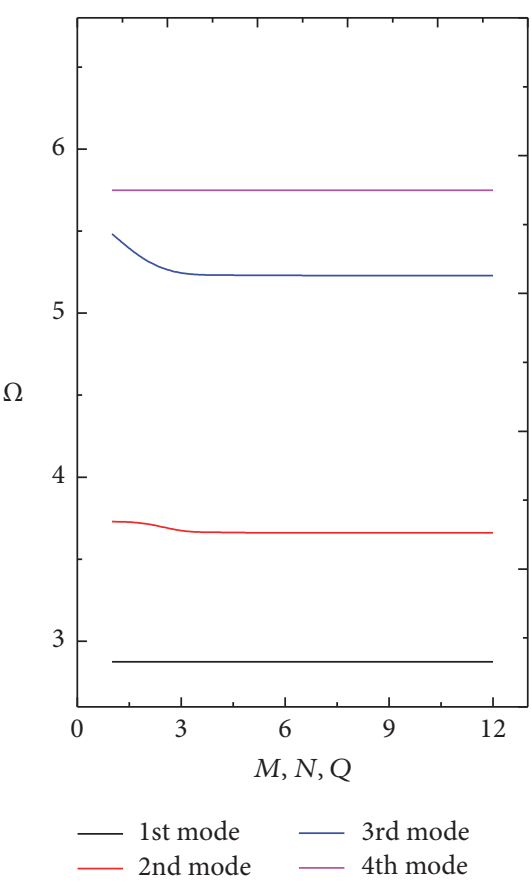

(b)

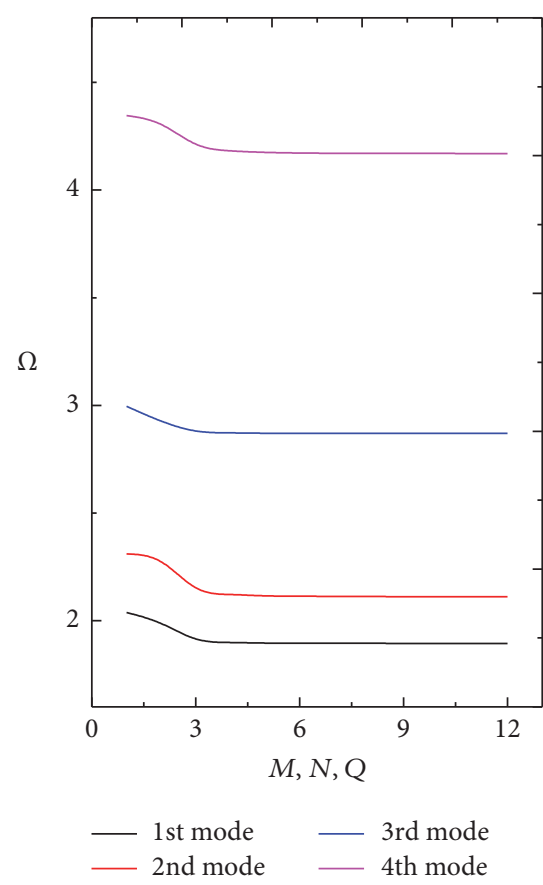

(c)

FIGURE 2: Convergence of frequency parameters $\Omega$ for a thick rectangular plate with different boundary conditions: (a) CCCC; (b) SSSS; (c) FFFF.

$$
\zeta_{z}^{2}(0)=\zeta_{z}^{2}(h)=\zeta_{z}^{\prime \prime}(0)=0, \quad \zeta_{z}^{\prime \prime}(h)=1 .
$$

Substituting (11) into (9) and then minimizing the functional $\prod$ with respect to the coefficients of the admissible functions, that is

$$
\begin{aligned}
& \frac{\partial \prod}{\partial \iota}=0, \\
& \qquad \iota=A_{m n}^{u}, a_{m}^{l}, b_{n}^{l}, B_{m n}^{v}, c_{m}^{l}, d_{n}^{l}, \ldots, E_{m n}^{y}, g_{m}^{l}, h_{n}^{l},
\end{aligned}
$$

the equations of motion for the rectangular plates can be yielded and are given in the matrix form:

$$
\begin{gathered}
\left(\left[\begin{array}{ccc}
{\left[\mathbf{K}_{u u}\right]} & {\left[\mathbf{K}_{u v}\right]} & {\left[\mathbf{K}_{u w}\right]} \\
{\left[\mathbf{K}_{u v}\right]^{T}} & {\left[\mathbf{K}_{v v}\right]} & {\left[\mathbf{K}_{v w}\right]} \\
{\left[\mathbf{K}_{u w}\right]^{T}} & {\left[\mathbf{K}_{v w}\right]^{T}} & {\left[\mathbf{K}_{w w}\right]}
\end{array}\right]\right. \\
\left.-\omega^{2}\left[\begin{array}{ccc}
{\left[\mathbf{M}_{u u}\right]} & \mathbf{0} & \mathbf{0} \\
\mathbf{0} & {\left[\mathbf{M}_{v v}\right]} & \mathbf{0} \\
\mathbf{0} & \mathbf{0} & {\left[\mathbf{M}_{w w}\right]}
\end{array}\right]\right)\left\{\begin{array}{l}
\{\mathbf{A}\} \\
\{\mathbf{B}\} \\
\{\mathbf{C}\}
\end{array}\right\}=\mathbf{0},
\end{gathered}
$$

where $\left[\mathbf{K}_{i j}\right]$ and $\left[\mathbf{M}_{i j}\right](i, j=u, v, w)$, respectively, represent the stiffness submatrix and mass submatrix. The column vectors of the unknown coefficients $\{\mathbf{A}\},\{\mathbf{B}\}$, and $\{\mathbf{C}\}$ are shown as follows:

$$
\begin{aligned}
\mathbf{A}= & \left\{A_{000}, \ldots, A_{m n q}, \ldots, A_{M N Q}, \ldots, a_{00}^{1}, \ldots, a_{M N}^{1}, a_{00}^{2},\right. \\
& \ldots, a_{M N}^{2}, a_{00}^{3}, \ldots, a_{M Q}^{3}, a_{00}^{4}, \ldots, a_{M Q}^{4}, a_{00}^{5}, \ldots, a_{N Q}^{5}, a_{00}^{6}, \\
& \left.\ldots, a_{N Q}^{6}\right\}
\end{aligned}
$$

$$
\begin{aligned}
\mathbf{B}= & \left\{B_{000}, \ldots, B_{m n q}, \ldots, B_{M N Q}, \ldots, b_{00}^{1}, \ldots, b_{M N}^{1}, b_{00}^{2}, \ldots,\right. \\
& b_{M N}^{2}, b_{00}^{3}, \ldots, b_{M Q}^{3}, b_{00}^{4}, \ldots, b_{M Q}^{4}, b_{00}^{5}, \ldots, b_{N Q}^{5}, b_{00}^{6}, \ldots, \\
& \left.b_{N Q}^{6}\right\}, \\
\mathbf{C}= & \left\{C_{000}, \ldots, C_{m n q}, \ldots, C_{M N Q}, \ldots, c_{00}^{1}, \ldots, c_{M N}^{1}, c_{00}^{2}, \ldots,\right. \\
& \left.c_{M N}^{2}, c_{00}^{3}, \ldots, c_{M Q}^{3}, c_{00}^{4}, \ldots, c_{M Q}^{4}, c_{00}^{5}, \ldots, c_{N Q}^{5}, c_{00}^{6}, \ldots, c_{N Q}^{6}\right\} .
\end{aligned}
$$

The exact natural frequencies and mode shapes of the rectangular plates can be easily obtained by solving (15).

\section{Numerical Results and Discussion}

Since the natural frequencies and mode shapes are obtained from the Ritz method and the number of terms of the admissible functions being chosen as infinity is unrealistic in the actual calculations, thus, it is very important to make the convergence study of the present method to understand the convergence rate and the accuracy of the method. For general purposes in the future, the nondimensional foundation parameters and frequency parameters are used for numerical results as follows: $K_{W}=K_{w} \times a^{4} / D, K_{S}=K_{s} \times a^{2} / D$, and $\Omega=$ $\omega b^{2}(\rho h / D)^{1 / 2}$, where $D=E h^{3} / 12 /\left(1-\mu^{2}\right)$. Figure 2 shows the convergence studies of the first four frequency parameters for a rectangular plate with CFCF boundary condition and different truncated numbers $M, N$, and $Q$. The geometrical dimensions of the plates are used: $a=1 \mathrm{~m}, b=2 \mathrm{~m}$, and $h=0.5 \mathrm{~m}$. The foundation coefficients are $K_{W}=10$ and $K_{S}=10$. It is observed that the proposed method has fast convergence and good stability. In view of the excellent 
TABLE 1: Comparison of the frequency parameters $\Omega$ for square thick plate with different boundary conditions.

\begin{tabular}{|c|c|c|c|c|c|c|c|c|c|}
\hline \multirow{2}{*}{$\mathrm{BC}$} & \multirow{2}{*}{$h / a$} & \multirow{2}{*}{ Method } & \multicolumn{7}{|c|}{ Mode number } \\
\hline & & & 1 & 2 & 3 & 4 & 5 & 6 & 7 \\
\hline \multirow{5}{*}{ SSSS } & \multirow{3}{*}{0.2} & Reference [20] & 17.528 & 32.192 & 32.192 & 38.502 & 38.502 & 45.526 & 55.843 \\
\hline & & Reference [17] & 17.526 & 32.192 & 32.192 & 38.483 & 38.483 & 45.526 & 55.787 \\
\hline & & Present & 17.525 & 32.184 & 32.184 & 38.480 & 38.480 & 45.526 & 55.781 \\
\hline & \multirow{2}{*}{0.5} & Reference [17] & 12.426 & 12.877 & 12.877 & 18.210 & 23.007 & 23.007 & 25.753 \\
\hline & & Present & 12.424 & 12.874 & 12.874 & 18.210 & 23.005 & 23.005 & 25.747 \\
\hline \multirow{5}{*}{$\mathrm{CCCC}$} & \multirow{3}{*}{0.2} & Reference [20] & 26.974 & 47.253 & 47.253 & 61.944 & 61.944 & 63.570 & 72.568 \\
\hline & & Reference [17] & 26.906 & 47.103 & 47.103 & 61.917 & 61.917 & 63.348 & 72.286 \\
\hline & & Present & 26.966 & 47.192 & 47.192 & 61.949 & 61.949 & 63.453 & 72.404 \\
\hline & \multirow{2}{*}{0.5} & Reference [17] & 15.294 & 24.078 & 24.078 & 24.823 & 24.823 & 29.377 & 31.210 \\
\hline & & Present & 15.305 & 24.088 & 24.088 & 24.826 & 24.826 & 29.373 & 31.522 \\
\hline \multirow{4}{*}{ FFFF } & \multirow{2}{*}{0.2} & Reference [18] & 11.710 & 17.433 & 21.252 & 27.647 & 27.647 & 40.191 & 42.776 \\
\hline & & Present & 11.719 & 17.436 & 21.254 & 27.659 & 27.659 & 40.192 & 42.776 \\
\hline & \multirow{2}{*}{0.5} & Reference [18] & 8.780 & 12.515 & 14.962 & 16.073 & 17.030 & 17.030 & 17.631 \\
\hline & & Present & 8.781 & 12.515 & 14.962 & 16.073 & 17.030 & 17.030 & 17.633 \\
\hline
\end{tabular}

TABLE 2: Comparison of the frequency parameters $\Omega$ for thick rectangular plate with different foundation coefficients.

\begin{tabular}{|c|c|c|c|c|c|c|c|c|}
\hline \multirow{2}{*}{$\mathrm{BC}$} & \multirow{2}{*}{$h / a$} & \multirow{2}{*}{$K_{W}$} & \multirow{2}{*}{$K_{S}$} & \multirow{2}{*}{ Method } & \multicolumn{4}{|c|}{ Mode number } \\
\hline & & & & & 1 & 2 & 3 & 4 \\
\hline \multirow{12}{*}{ SSSS } & \multirow{6}{*}{0.01} & \multirow{3}{*}{100} & \multirow{3}{*}{10} & Reference [48] & 2.6551 & 5.5717 & 5.5717 & 8.5406 \\
\hline & & & & Reference [50] & 2.6551 & 5.5718 & 5.5718 & 8.5405 \\
\hline & & & & Present & 2.6551 & 5.5717 & 5.5717 & 8.5404 \\
\hline & & \multirow{3}{*}{500} & \multirow{3}{*}{10} & Reference [48] & 3.3398 & 5.9285 & 5.9285 & 8.7775 \\
\hline & & & & Reference [50] & 3.3400 & 5.9287 & 5.9287 & 8.7775 \\
\hline & & & & Present & 3.3400 & 5.9287 & 5.9287 & 8.7774 \\
\hline & \multirow{6}{*}{0.1} & \multirow{3}{*}{200} & \multirow{3}{*}{10} & Reference [48] & 2.7756 & 5.2954 & 5.2954 & 7.7279 \\
\hline & & & & Reference [50] & 2.7842 & 5.3043 & 5.3043 & 7.7287 \\
\hline & & & & Present & 2.7837 & 5.3013 & 5.3013 & 7.7215 \\
\hline & & \multirow{3}{*}{1000} & \multirow{3}{*}{10} & Reference [48] & 3.9566 & 5.9757 & 5.9757 & 8.1954 \\
\hline & & & & Reference [50] & 3.9805 & 6.0078 & 6.0078 & 8.2214 \\
\hline & & & & Present & 3.9802 & 6.0052 & 6.0052 & 8.2148 \\
\hline \multirow{3}{*}{$\mathrm{CCCC}$} & \multirow{3}{*}{0.015} & \multirow{3}{*}{1390.2} & \multirow{3}{*}{166.83} & Reference [48] & 8.1675 & 12.8230 & 12.8230 & 16.8330 \\
\hline & & & & Reference [50] & 8.1375 & 12.8980 & 12.8980 & 16.9320 \\
\hline & & & & Present & 8.1397 & 12.8995 & 12.8995 & 13.9349 \\
\hline
\end{tabular}

numerical behavior of the current solution, the truncation numbers will be simply set as $M=N=Q=12$ in Figure 2.

Next, the comparison study will be carried out by the present method and other methods presented in the existing publications. Table 1 shows the comparison of the first seven frequency parameters $\Omega$ for a square thick plate with SSSS, CCCC, and FFFF boundary conditions. In this example, the thick plate is without considering the foundation parameters. In order to check the present method, the results are compared with other published solutions by using the 3D Ritz method with general orthogonal polynomials [17], the 3D Ritz method with general orthogonal polynomials using the Gram-Schmidt process [18], and the 3D Ritz method with simple algebraic polynomials [20]. From the comparison, we can see a consistent agreement of the results taken from the current method and referential data.

Furthermore, the rectangular thick plate with various boundary conditions and elastic foundations is examined. Comparison is presented in Table 2. In this table, first four frequency parameters $\Omega$ are obtained for various boundary conditions and foundation coefficients according to the present formulation and compared with those given by Zhou et al. [48] and Omurtag et al. [50] based on different numerical methods and elastic theories. It is observed that the frequencies are in excellent agreement with those obtained from FEM, which verifies the accuracy and efficiency of the proposed model.

From Figure 2 and Tables 1 and 2, we can draw the conclusion that the present approach has good convergence and excellent accuracy and reliability to study the vibration 

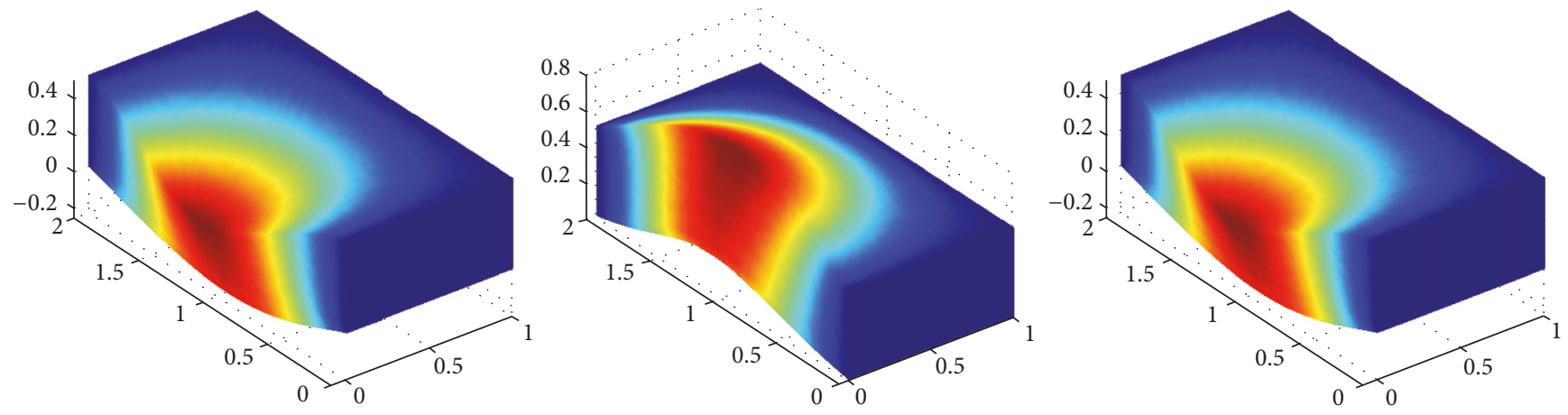

$k_{i}=10^{4}$

$$
k_{i}=10^{6}
$$

$k_{i}=10^{8}$
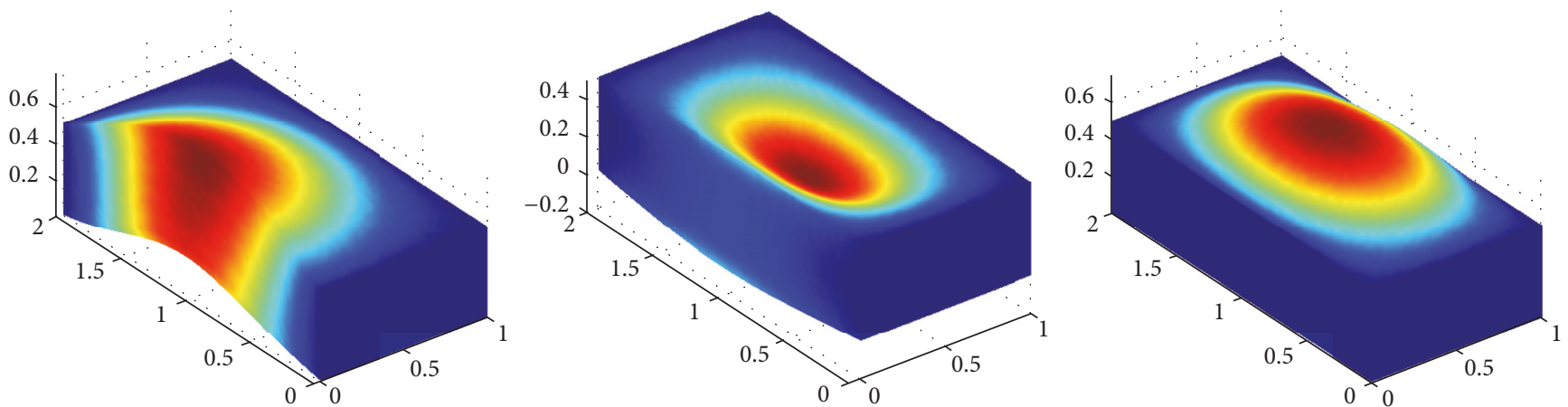

$$
k_{i}=10^{10}
$$$$
k_{i}=10^{12}
$$$$
k_{i}=10^{14}
$$

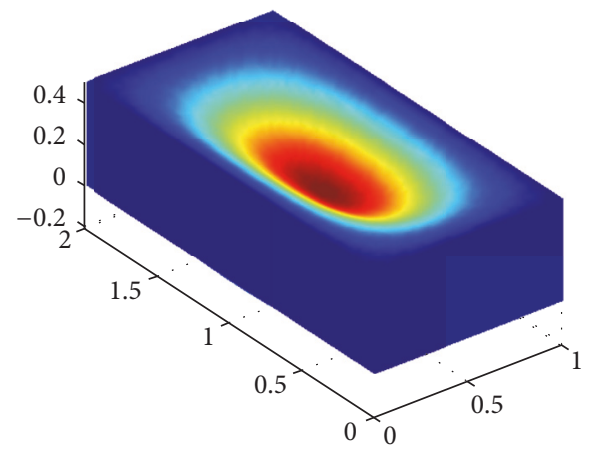

$k_{i}=10^{16}$

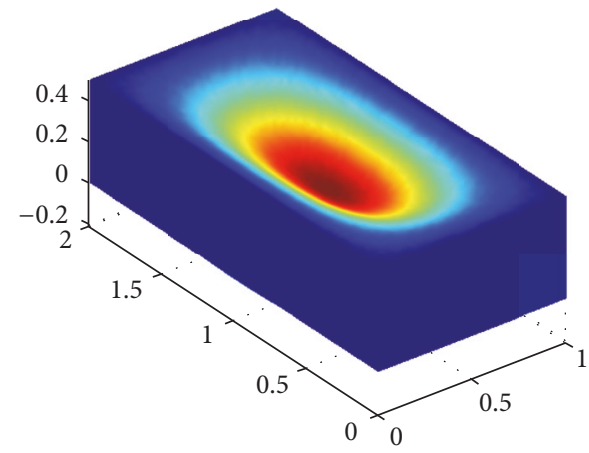

$k_{i}=10^{20}$

Figure 3: The corresponding fundamental mode shapes of Table 3.

analysis of rectangular thick plates on Pasternak foundation with arbitrary boundary conditions. Thus, based on the comparison studies, the first known results of rectangular thick plates rested on Pasternak foundation with various elastic boundary conditions as well as foundation coefficients are presented in Table 3. The geometrical dimensions of the plates are the same as those in Figure 1. The boundary condition is clamped at $y=$ constants and $x=0$; and the elastic restraints on the $x=a$ are uniformly $\left(k_{u}=k_{v}=k_{w}\right)$ changed from $10^{4}$ to $10^{20}$. From the table, first we can see that the frequency parameters gradually increase as the elastic restraints increase and then they almost keep unchanged while the stiffness is larger than $10^{18}$. In order to enhance the understanding of the phenomenon, the corresponding fundamental mode shapes of Table 3 are depicted in Figure 3. From Figure 3, it is directly seen that the boundary elastic restraints have a significant effect on the vibration behavior of the rectangular thick plate.

Lastly, the influence of the foundation coefficients of the Pasternak foundation on the rectangular thick plates subjected to various boundary conditions is reported for the first time, as shown in Figure 4 . The elastic boundary condition is defined as $k_{w}=k_{v}=k_{w}=10^{10}$. The geometric parameters are the same as Figure 2 . It can be easily obtained that, regardless of the boundary conditions of the rectangular thick plates, there exists a certain range of the 
TABLE 3: The first frequency parameters $\Omega$ for rectangular thick plate with different elastic boundary condition and foundation coefficient.

\begin{tabular}{|c|c|c|c|c|c|c|c|c|}
\hline \multirow{2}{*}{$k_{u}=k_{v}=k_{w}$} & \multicolumn{4}{|c|}{$\left(K_{W}, K_{S}\right)=(10,10)$} & \multicolumn{4}{|c|}{$\left(K_{W}, K_{S}\right)=(100,10)$} \\
\hline & 1 & 2 & 3 & 4 & 1 & 2 & 3 & 4 \\
\hline $10^{4}$ & 3.0361 & 4.8053 & 4.9183 & 5.1693 & 3.3626 & 4.9027 & 4.9199 & 5.1746 \\
\hline $10^{6}$ & 3.0361 & 4.8053 & 4.9183 & 5.1693 & 3.3627 & 4.9027 & 4.9200 & 5.1746 \\
\hline $10^{8}$ & 3.0381 & 4.8064 & 4.9191 & 5.1701 & 3.3645 & 4.9038 & 4.9208 & 5.1754 \\
\hline $10^{10}$ & 3.2188 & 4.9129 & 5.0023 & 5.2473 & 3.5330 & 5.0040 & 5.0084 & 5.2530 \\
\hline $10^{12}$ & 4.9669 & 6.2598 & 6.8032 & 7.8515 & 5.1577 & 6.3305 & 6.8046 & 7.8518 \\
\hline $10^{14}$ & 5.4078 & 6.5994 & 7.1711 & 8.3654 & 5.5706 & 6.6627 & 7.1724 & 8.3907 \\
\hline $10^{16}$ & 5.4959 & 6.6322 & 7.1760 & 8.3794 & 5.6004 & 6.6785 & 7.1770 & 8.3992 \\
\hline $10^{18}$ & 5.5041 & 6.6356 & 7.1761 & 8.3808 & 5.6037 & 6.6801 & 7.1771 & 8.4000 \\
\hline $10^{20}$ & 5.5041 & 6.6356 & 7.1761 & 8.3808 & 5.6037 & 6.6801 & 7.1771 & 8.4000 \\
\hline
\end{tabular}
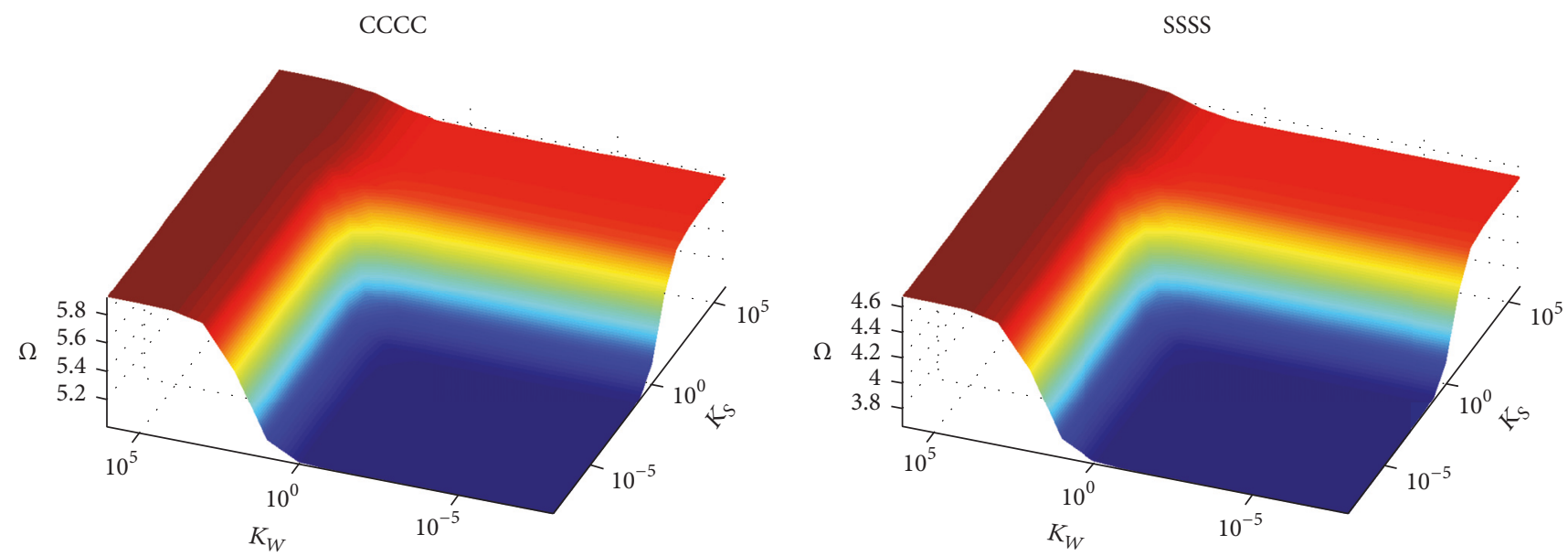

EEEE

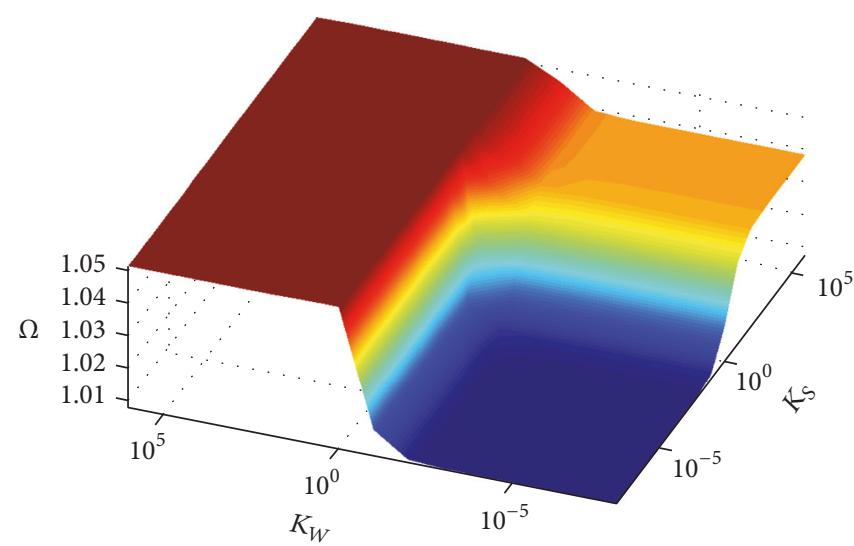

FIGURE 4: Variation of the frequency parameters $\Omega$ versus the elastic foundation coefficients for rectangular thick plates with different boundary conditions.

elastic foundation coefficients during which the frequency parameter $\Omega$ increases and out of which the influence on frequency parameter $\Omega$ is negligible.

\section{Conclusions}

In this paper, a unified method is developed for the vibration analysis of the rectangular thick plates on Pasternak foundation with arbitrary boundary conditions based on the linear, small-strain 3D elasticity theory. The method combines the advantages of the Ritz method and the modified Fourier expansion. Under the current framework, regardless of boundary conditions, each displacement function of the plate is expanded as the superposition of a standard threedimensional cosine Fourier series and several auxiliary functions are introduced to remove any potential discontinuousness of the original rectangular plates unknown and its derivatives at the edges. The good convergence and excellent 
accuracy and reliability are checked and validated by the comparison with the results presented by other contributors. New results for free vibration of rectangular thick plates with elastic boundary conditions are presented, which may be used for benchmarking of researchers in the field. In addition, by means of the influences of elastic restrain parameters and foundation coefficients on free vibration characteristic of the rectangular thick plates, we can know that the frequency parameters increase rapidly as the restraint parameters and foundation coefficients increase in the certain range.

\section{Conflicts of Interest}

The authors declare that there are no conflicts of interest regarding the publication of this paper.

\section{Acknowledgments}

The authors gratefully acknowledge the financial support from the National Natural Science Foundation of China (no. 61633008 and no. 61503073) and the Natural Research Fund of Jilin Province (no. 20170101125JC).

\section{References}

[1] S. Timoshenko and S. Woinowsky-Krieger, Theory of Plates and Shells, 1959.

[2] R. D. Mindlin, "Influence of rotary inertia and shear on flexural motions of isotropic, elastic plates," Journal of Applied Mechanics, vol. 18, pp. 1031-1036, 1951.

[3] R. D. Mindlin, A. Schacknow, and H. Deresiewicz, "Flexural vibrations of rectangular plates," vol. 23, no. 3, pp. 430-436, 1956.

[4] N. F. Hanna and A. W. Leissa, "A higher order shear deformation theory for the vibration of thick plates," Journal of Sound and Vibration, vol. 170, no. 4, pp. 545-555, 1994.

[5] J. N. Reddy, "A simple higher order theory for laminated composite plates," Journal of Applied Mechanics, vol. 51, no. 4, pp. 745-752, 1984.

[6] Q. Wang, D. Shi, Q. Liang, and X. Shi, "A unified solution for vibration analysis of functionally graded circular, annular and sector plates with general boundary conditions," Composites Part B: Engineering, vol. 88, pp. 264-294, 2016.

[7] Q. Wang, D. Shi, and X. Shi, "A modified solution for the free vibration analysis of moderately thick orthotropic rectangular plates with general boundary conditions, internal line supports and resting on elastic foundation," Meccanica, vol. 51, no. 8, pp. 1985-2017, 2016.

[8] Q. Wang, D. Shi, F. Pang, and F. e Ahad, "Benchmark solution for free vibration of thick open cylindrical shells on Pasternak foundation with general boundary conditions," Meccanica, vol. 52, no. 1, pp. 457-482, 2017.

[9] S. Srinivas, C. V. Joga Rao, and A. K. Rao, "An exact analysis for vibration of simply-supported homogeneous and laminated thick rectangular plates," Journal of Sound and Vibration, vol. 12, no. 2, pp. 187-199, 1970.

[10] Y. K. Cheung and S. Chakrabarti, "Free vibration of thick, layered rectangular plates by a finite layer method," Journal of Sound and Vibration, vol. 21, no. 3, pp. 277-284, 1972.
[11] J. R. Hutchinson and S. D. Zillmer, "Vibration of a free rectangular parallelepiped," Journal of Applied Mechanics, Transactions ASME, vol. 50, no. 1, pp. 123-130, 1983.

[12] J. A. Fromme and A. W. Leissa, "Free vibration of the rectangular parallelepiped," Journal of the Acoustical Society of America, vol. 48, no. 1, pp. 290-298, 1970.

[13] M. Malik and C. W. Bert, "Three-dimensional elasticity solutions for free vibrations of rectangular plates by the differential quadrature method," International Journal of Solids and Structures, vol. 35, no. 3-4, pp. 299-318, 1998.

[14] K. M. Liew and T. M. Teo, "Three-dimensional vibration analysis of rectangular plates based on differential quadrature method," Journal of Sound and Vibration, vol. 220, no. 4, pp. 577-599, 1999.

[15] K. M. Liew, T. M. Teo, and J.-B. Han, "Comparative accuracy of DQ and HDQ methods for three-dimensional vibration analysis of rectangular plates," International Journal for Numerical Methods in Engineering, vol. 45, no. 12, pp. 1831-1848, 1999.

[16] A. Leissa and Z.-D. Zhang, "On the three-dimensional vibrations of the cantilevered rectangular parallelepiped," Journal of the Acoustical Society of America, vol. 73, no. 6, pp. 2013-2021, 1983.

[17] K. M. Liew, K. C. Hung, and M. K. Lim, "A continuum threedimensional vibration analysis of thick rectangular plates," International Journal of Solids and Structures, vol. 30, no. 24, pp. 3357-3379, 1993.

[18] K. M. Liew, K. C. Hung, and M. K. Lim, "Free vibration studies on stress-free three-dimensional elastic solids," Journal of Applied Mechanics, vol. 62, no. 1, pp. 159-165, 1995.

[19] K. M. Liew, K. C. Hung, and M. K. Lim, “Three-dimensional vibration of rectangular plates: effects of thickness and edge constraints," Journal of Sound and Vibration, vol. 182, no. 5, pp. 709-727, 1995.

[20] K. Itakura, "Free vibration analysis of thick skewed plates having arbitrary boundary conditions," Journal of Structural and Construction Engineering (Transactions of AIJ), vol. 62, no. 492, pp. 37-45, 1997.

[21] C. W. Lim, S. Kitipornchai, and K. M. Liew, "Numerical aspects for free vibration of thick plates. Part II: numerical efficiency and vibration frequencies," Computer Methods in Applied Mechanics and Engineering, vol. 156, no. 1-4, pp. 31-44, 1998.

[22] C. W. Lim, K. M. Liew, and S. Kitipornchai, "Numerical aspects for free vibration of thick plates. Part I: formulation and verification," Computer Methods in Applied Mechanics and Engineering, vol. 156, no. 1-4, pp. 15-29, 1998.

[23] D. Zhou, Y. K. Cheung, F. T. K. Au, and S. H. Lo, "Threedimensional vibration analysis of thick rectangular plates using Chebyshev polynomial and Ritz method," International Journal of Solids and Structures, vol. 39, no. 26, pp. 6339-6353, 2002.

[24] P. L. Pasternak, "On a new method of analysis of an elastic foundation by means of two foundation constants," Gosudarstvennoe Izdatelstvo Literaturi Po Stroitelstvu I Arkhitekture, pp. 1-56, 1954.

[25] H. S. Shen, J. Yang, and L. Zhang, "Free and forced vibration of Reissner-Mindlin plates with free edges resting on elastic foundations," Journal of Sound and Vibration, vol. 244, no. 2, pp. 299-320, 2001.

[26] A. Kutlu, B. Uğurlu, M. H. Omurtag, and A. Ergin, "Dynamic response of Mindlin plates resting on arbitrarily orthotropic Pasternak foundation and partially in contact with fluid," Ocean Engineering, vol. 42, pp. 112-125, 2012. 
[27] E. Winkler, Die Lehre von der Elastizität und Festigkeit, 1867.

[28] K. Zhang, D. Shi, W. Wang, and Q. Wang, "Mechanical characterization of hybrid lattice-to-steel joint with pyramidal CFRP truss for marine application," Composite Structures, vol. 160, pp. 1198-1204, 2017.

[29] H. Zhang, D. Shi, and Q. Wang, "An improved Fourier series solution for free vibration analysis of the moderately thick laminated composite rectangular plate with non-uniform boundary conditions," International Journal of Mechanical Sciences, vol. 121, pp. 1-20, 2017.

[30] Q. Wang, D. Shi, Q. Liang, and F. Pang, "Free vibration of four-parameter functionally graded moderately thick doublycurved panels and shells of revolution with general boundary conditions," Applied Mathematical Modelling, vol. 42, pp. 705734, 2017.

[31] Q. Wang, D. Shi, Q. Liang, F. Pang et al., "Free vibrations of composite laminated doubly-curved shells and panels of revolution with general elastic restraints," Applied Mathematical Modelling, vol. 46, pp. 227-262, 2017.

[32] D. Shao, S. Hu, Q. Wang, and F. Pang, "An enhanced reverberation-ray matrix approach for transient response analysis of composite laminated shallow shells with general boundary conditions," Composite Structures, vol. 162, pp. 133-155, 2017.

[33] D. Shao, S. Hu, Q. Wang, and F. Pang, "Free vibration of refined higher-order shear deformation composite laminated beams with general boundary conditions," Composites Part B: Engineering, vol. 108, pp. 75-90, 2017.

[34] Q. Wang, D. Shi, Q. Liang, and F. e Ahad, "A unified solution for free in-plane vibration of orthotropic circular, annular and sector plates with general boundary conditions," Applied Mathematical Modelling, vol. 40, no. 21-22, pp. 9228-9253, 2016.

[35] Q. Wang, D. Shi, Q. Liang, and F. Ahad, "An improved Fourier series solution for the dynamic analysis of laminated composite annular, circular, and sector plate with general boundary conditions," Journal of Composite Materials, vol. 50, no. 30, pp. 41994233, 2016.

[36] Q. Wang, D. Shi, and Q. Liang, "Free vibration analysis of axially loaded laminated composite beams with general boundary conditions by using a modified Fourier-Ritz approach," Journal of Composite Materials, vol. 50, no. 15, pp. 2111-2135, 2016.

[37] D. Shao, S. Hu, Q. Wang, and F. Pang, "A unified analysis for the transient response of composite laminated curved beam with arbitrary lamination schemes and general boundary restraints," Composite Structures, vol. 154, pp. 507-526, 2016.

[38] D. Shao, F. Hu, Q. Wang, F. Pang, and S. Hu, "Transient response analysis of cross-ply composite laminated rectangular plates with general boundary restraints by the method of reverberation ray matrix," Composite Structures, vol. 152, pp. 168-182, 2016.

[39] D. Shi, Q. Wang, X. Shi, and F. Pang, "A series solution for the in-plane vibration analysis of orthotropic rectangular plates with non-uniform elastic boundary constraints and internal line supports," Archive of Applied Mechanics, vol. 85, no. 1, pp. 51-73, 2015.

[40] Q. Wang, D. Shi, Q. Liang, and F. Pang, "A unified solution for vibration analysis of moderately thick, functionally graded rectangular plates with general boundary restraints and internal line supports," Mechanics of Advanced Materials and Structures, vol. 24, no. 11, pp. 961-973, 2017.

[41] T. Ye, G. Jin, Z. Su, and Y. Chen, "A modified Fourier solution for vibration analysis of moderately thick laminated plates with general boundary restraints and internal line supports," International Journal of Mechanical Sciences, vol. 80, pp. 29-46, 2014.

[42] T. Ye, G. Jin, and Z. Su, “Three-dimensional vibration analysis of laminated functionally graded spherical shells with general boundary conditions," Composite Structures, vol. 116, no. 1, pp. 571-588, 2014.

[43] T. Ye, G. Jin, S. Shi, and X. Ma, “Three-dimensional free vibration analysis of thick cylindrical shells with general end conditions and resting on elastic foundations," International Journal of Mechanical Sciences, vol. 84, pp. 120-137, 2014.

[44] Z. Su, G. Jin, and T. Ye, "Free vibration analysis of moderately thick functionally graded open shells with general boundary conditions," Composite Structures, vol. 117, no. 1, pp. 169-186, 2014.

[45] D. Shi, Q. Wang, X. Shi, and F. Pang, "An accurate solution method for the vibration analysis of Timoshenko beams with general elastic supports," Proceedings of the Institution of Mechanical Engineers. Part C: Journal of Mechanical Engineering Science, vol. 229, no. 13, pp. 2327-2340, 2014.

[46] D. Shi, Y. Zhao, Q. Wang, X. Teng, and F. Pang, "A unified spectro-geometric-ritz method for vibration analysis of open and closed shells with arbitrary boundary conditions," Shock and Vibration, vol. 2016, Article ID 4097123, 30 pages, 2016.

[47] Q. Wang, D. Shi, F. Pang, and Q. Liang, "Vibrations of composite laminated circular panels and shells of revolution with general elastic boundary conditions via Fourier-Ritz method," Curved and Layered Structures, vol. 3, no. 1, pp. 105-136, 2016.

[48] D. Zhou, Y. K. Cheung, S. H. Lo, and F. T. K. Au, "Threedimensional vibration analysis of rectangular thick plates on Pasternak foundation," International Journal for Numerical Methods in Engineering, vol. 59, no. 10, pp. 1313-1334, 2004.

[49] D. Zhou, S. H. Lo, F. T. K. Au, and Y. K. Cheung, "Threedimensional free vibration of thick circular plates on Pasternak foundation," Journal of Sound and Vibration, vol. 292, no. 3-5, pp. 726-741, 2006.

[50] M. H. Omurtag, A. Özütok, A. Y. Aköz, and Y. Özçelikörs, "Free vibration analysis of Kirchhoff plates resting on elastic foundation by mixed finite element formulation based on Gâteaux differential," International Journal for Numerical Methods in Engineering, vol. 40, no. 2, pp. 295-317, 1997. 


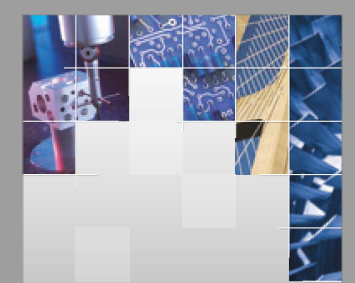

\section{Enfincering}
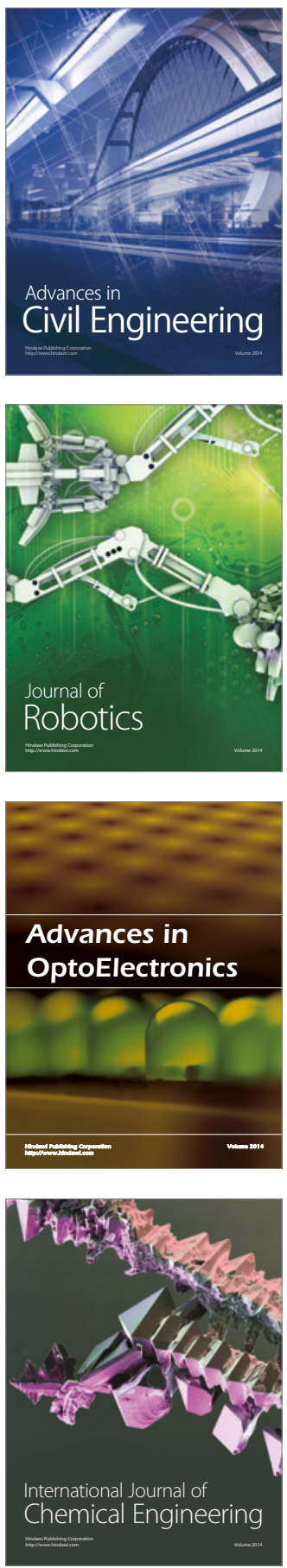

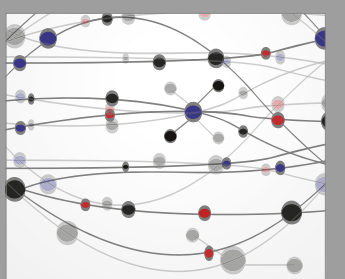

The Scientific World Journal

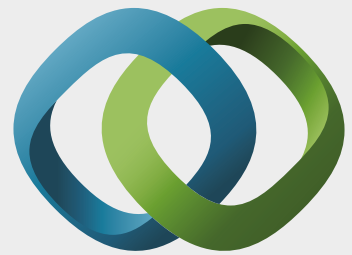

\section{Hindawi}

Submit your manuscripts at

https://www.hindawi.com
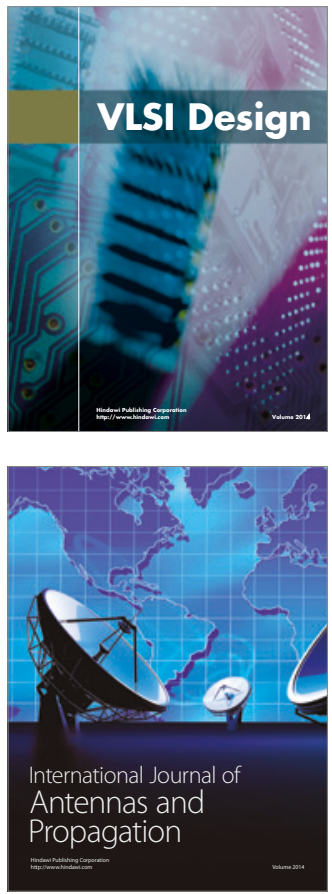

\section{Rotating}

Machinery
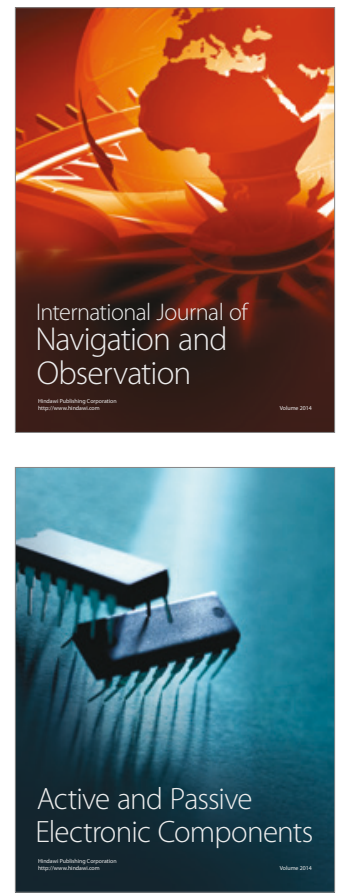
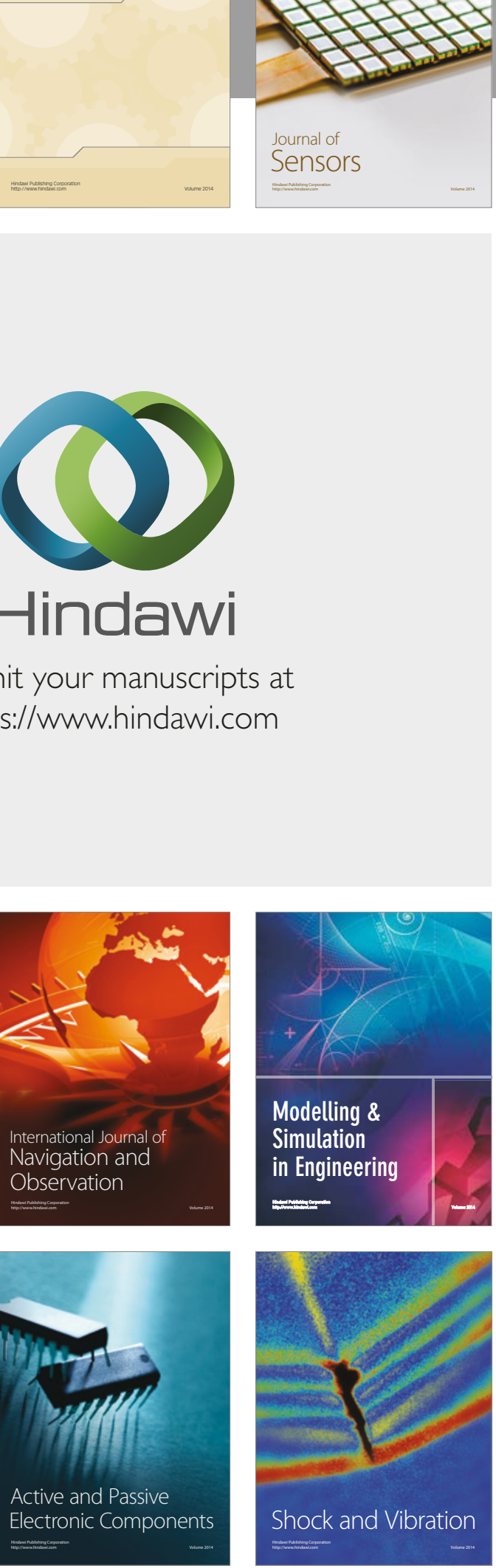
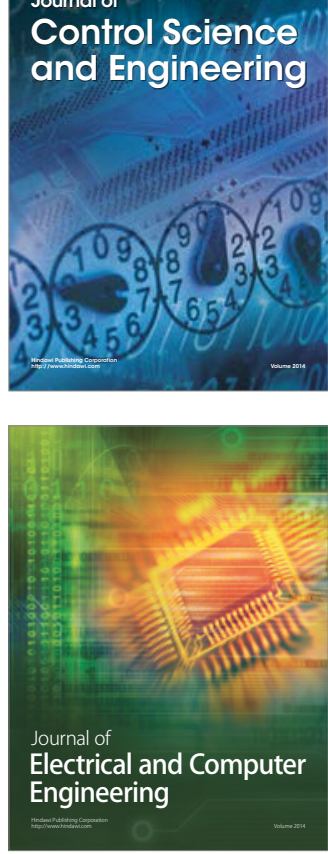

Distributed

Journal of

Control Science

and Engineering
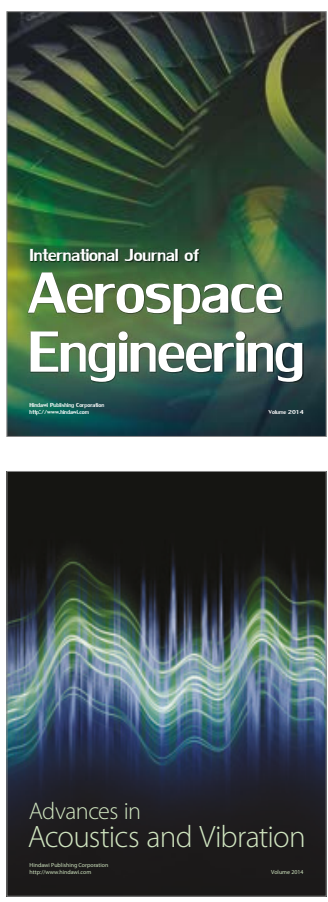

Sensor Networks 